\title{
An empirical investigation on the existence of weak form efficiency: The case of Karachi stock exchange
}

\author{
Bilal Nawaz ${ }^{\mathrm{a}}$, Asma Sarfraz ${ }^{\mathrm{a}}$, Haroon Hussain ${ }^{\mathrm{b}}$ and Mohsin Altaf ${ }^{*}$
}

${ }^{a}$ Student Scholar, Department of Commerce, University of Sargodha, Pakistan

${ }^{b}$ Assistant Professor, Department of Commerce University of Sargodha, Pakistan

${ }^{c}$ Lecturer, Department of Commerce, University of Sargodha, Pakistan

\begin{tabular}{l}
\hline A R T I C L E I N F O \\
\hline Article history: \\
Received March 25, 2012 \\
Received in revised format \\
17 October 2012 \\
Accepted 17 October 2012 \\
Available online \\
October 182012 \\
\hline Keywords: \\
Weak form efficiency \\
Augumented dickey fuller \\
Phillips perron \\
Kolmogrov-Smirnov
\end{tabular}

\section{A B S T R A C T}

This research study focuses the existence of "weak form efficiency" in the Karachi stock exchange of Pakistan. Daily stock returns are used to check the "weak form efficiency' in KSE covering a time period of 15 years ranges from July, 1997 to April, 2012. Kolmogrov-Smirnov (K-S) test, runs test, Unit root test Augumented Dickey Fuller test, Phillips Perron test are run to check the hypothesis. It is revealed that the KSE is not distributed normally and patterns are there in the prices so, the technical analyst can get the benefit in short run through predicting the future prices. This means that there exists some opportunity for the traders and investors to predict the upcoming stock prices of the securities, which are trading in the KSE and can earn high return and outperform the market. However, in long run scenario (in monthly data) the results are vice versa and Karachi stock exchange is a weak form efficient market.

\section{Introduction}

"Market Efficiency" has become an important debate for the investors and financers for the past few decades. As the world becomes a global village this makes it easy for the financers and investors to do investment wherever they want. Today, the investors are well aware which market will give more profit and which will not. Investors always try to earn the maximum return but it does not mean that they ignore the low capital stock because it is proved from the history that low capital stock outperform the markets. Today, the stock markets have become very efficient in getting the information related to the share prices because the information is costless. The sources of getting the information may be from the historical prices, beliefs, balance sheet information or from the events. Efficient market means getting the "fair value" for the security that the share prices reflect all available information, which is prevailing in the market. Market efficiency means that information in 
market do not expose off at once and it should be expose slowly in the market. Market efficiency depends on how well the investor gets the information of the share price. Fama defines the "Efficient market hypothesis as: A market in which prices at any time "fully reflect" available information is called "efficient" (Fama, 1970, p 383). Fama (1970) elaborates the "Efficient market hypothesis $(\mathrm{EMH})$ " into three forms of , first is "weak -form EMH" which means such market where the historical prices information reflects in the today's share prices hence fundamental analyst can take advantage from that market. Second is the "Semi-strong form of EMH" means that historical price and all announced public information reflect the share price and third one is "strong- form of EMH", which means that all sources of information such as historical prices, all announced information, events and insider information reflect the share price. As we are talking about the weak form efficiency in this paper, we will elaborate this term firstly. A market is said to be weak form efficient when the current share prices reflects the market data of past. If the securities in the market are weak form efficient than the historical prices of share will reflects from the current price of share that mean it has no value/worth for the technical analyst. Weak form efficient market hypothesis EMH is associated with random walk hypothesis but it is not identical to. Random walk hypothesis means that the stock prices moves randomly having no patterns. Technical analyst cannot get the benefit from the "weak form of EMH" because they predict the future stock prices from the historical data but the fundamental analyst, which do not predict the stock price from historical data and believes that stock prices are independent, can earn the high returns and can outperform the market. If the market is not weak form efficient, its means patterns are there and technical analyst can also get the benefit from that market.

The purpose of the study to find out that Karachi stock exchange of Pakistan is weak form efficient or not? K-S test, unit root test and run tests are applied to check out the hypothesis and the results disclose that KSE-100 index is weak form efficient in long-term scenario. Further results explain KS100 index is normally distributed in monthly stock returns but not normally distributed in weekly and daily stock returns.

This paper is divided into four sections: First section exhibits the introduction, second section exhibits the literature Review, third section exhibits the data and methodology, fourth exhibit the results/consequences of the research and the fifth part having conclusion.

\section{Literature review}

Brown and Easton (1988) examined the weak form efficiency in the London stock market. They took the 10,000 daily stock prices from 1821-1860 and applied run test and correlation test to check the weak from efficiency. The result showed that there exists weak form efficiency. Therefore, the technical analyst cannot get the benefit from the Landon stock market, but the fundamental analyst can outperform the market. Srinivasan (2010) examined the random walk hypothesis to find out the existence of weak form efficiency in two Indian stock markets i.e. National stock market (SENSEX) and Bombay stock market (S\&P CNX Nifty) covering the time span is of 12 years from $1^{\text {st }} \mathrm{July,} 1997$ to $31^{\text {st }}$ August, 2010 by using the daily stock prices. Unit root analysis, augmented dickey fuller test and Phillps Perron tests were applied to check the weak form efficiency. Results showed that Indian stocks markets are not weak form efficient, which means there exists some opportunity for investors to forecast the future prices and earn high returns.

Mobarek and Keasey (2000) investigated the weak form efficiency in the stock market of Bangladesh by taking the daily stock prices of Dhaka stock exchange covering a period from 1988-1997. Kolmogrov-smirnov normality test and run test were implemented to check the existence of weak form efficiency and the results showed that there was no weak form efficiency in Dhaka Stock Exchange. Suleman et al. (2010) studied the stock markets of some major Asian countries and Australia i.e. Pakistan, Thailand, India, China, Singapore, Malaysia, Sri Lanka, Hong Kong, Korea, Indonesia, Taiwan, Philippine by taking the monthly stock prices of these countries covering a time 
span from 2004 to 2009 Auto-correlation, Q Statistics test. Ljung box test, run test, variance ratio and unit root analysis were use to find out the weak form efficiency in the above listed stock markets. Results showed that that the monthly returns of these stock markets were not distributed normally and the traders could get the stream of advantages through arbitrage technique.

Angelov (2009) investigated the existence of weak form efficiency in the Bulgarian stock exchange. Daily and monthly prices of individual securities, which were trading in the Bulgarian stock markets covering a time period of 2000 to 2006. Statistical techniques such as auto correlation and variance were applied to check the validity of weak form efficiency, but the results proved that Bulgarian stock market was not weak form efficient. Niblock and Sloan (2007) studied whether China's stock markets (Shanghai "A" Shanghai "B", Shenzhen "A", Shenzhen "B", Dow Jones and Hang Seng) were weak form efficient or not. They used the industrial average's stock indices over the period of 2002-2005. Serial correlation coefficient tests, run test variance ratio test, co-integration test and granger tests were applied to find out that these markets were weak form efficient but results showed that China's markets were not weak form efficient.

Rehman and Hossain (2006) examined the stock markets of Bangladesh to see whether the Dhaka stock exchange was weak form efficient or not. They used daily stock prices of 33 companies covering a time span of 12 years from1994 to 2005. K-S test (Kolmogrov-Smirnov test), run test, Lilliefors test, and parametric-tests were run and results depicted that Dhaka stock markets were not weak form efficient. Worthington and Higgs (2006) investigated the weak-form efficiency in the Asian stock markets using the daily stock returns of emerging Asian markets and the developed markets i.e. Hong Kong, New Zealand, Australia and Japan. To test the hypothesis serial correlation coefficient technique, unit root technique, run test, shin unit root technique, Kwiatkowski, and multiple variance techniques were used to check whether the data was distributed normally or not and the results showed that these above mentioned markets were not weak form efficient.

Panday (2003) examined the weak form efficiency in Indian stock market using daily stocks returns data, which covered the time period of Jan, 1996 to Jun, 2002. Runs test and autocorrelation techniques were applied to check whether Indian stock market was efficient or inefficient. Results proved that Indian stock market was inefficient, which means technical analyst can predict the future prices and get the benefit out of that. Moustafa (2004) investigated the stock returns of United Arab Emirates, using the daily return of forty three (43) stocks for the period of two year from Oct, 2001 to Sep, 2003. Runs test and normality test were used to achieve the said purpose. Results were astonished from conventional views describe that forty stocks were normally distributed and other three were not normally distributed. UAE market has required further research with long run stock prices.

\section{Data and Methodology}

Data employed in this paper consist of Daily, weekly and monthly share prices of Karachi stock exchange covering a time period of 15 years. Data commence from July, 1997 and ends at April, 2012. This data has been taken from yahoo finance. Firstly we take the natural log of the closing prices then take the natural returns of the closing share prices. Returns of the market can be calculated through the following formula:

$M R T=\operatorname{Ln}(M R T / M R T-1)$,

where MRT is market return, MRT is market return of price index at time "T", MRT-1 is Market return of price index at time period "T-1" and Ln is the natural log. 


\subsection{Descriptive statistics}

Descriptive statistics describes about the mean, median, std. deviation, skewness, range and kurtosis, which tell us about the behavior of the daily, weekly and monthly data.

\subsection{Unit root test}

Unit root test is run in this paper because the data was not stationary so to make it stationary, Augmented Dickey fuller (1979) and Phillips Perron (1988) test are applied which make the daily, weekly and monthly data stationary not at level but make it stationary at $1^{\text {st }}$ difference.

\subsection{Kolomogrov-Smirnov}

Non-parametric test that is Kolomogrov-Smirnov test is used to check that how data fits to the specific distribution (normal or not normal).

\subsection{Run test}

Run test is applied in this research to check the serial inter dependency of market return. Wallis and Robert (1956) gives the formula of expected number of run?

\subsection{Sample period}

Sample period consist of 15years commence from July 1997 and ends at April 2012.

\subsection{Sample size}

Sample size includes the Daily (3598) observations, weekly (762) observations and monthly (177) observations.

\section{Empirical results and the Hypothesis}

\subsection{Hypothesis}

$\mathrm{H}_{0}=$ Market is weak form efficient means KSE is normally distributed.

$\mathrm{H}_{1}=$ Market is not weak form efficient means KSE is not normally distributed.

\subsection{Descriptive data}

$\mathrm{N}=3598$ (Observations Daily) N= 762 (Observations Weekly) N=177 (Observations Monthly)

Table 1 describes the results of descriptive statistics of returns of Karachi stock exchange of Pakistan. A vigilant study of descriptive statistics expose that average daily returns is $0.06 \%$, weekly average returns are $0.28 \%$ and monthly average returns are $1.09 \%$. The standard deviation of daily return is $1.69 \%$, weekly $3.93 \%$ and monthly $9.68 \%$. Market is negatively skewed in all daily, weekly and monthly data.

\section{Table 1}

Basic statistics

\begin{tabular}{ccccccccc}
\hline Variable & Mean & Median & Std. & Minimum & Maximum & Range & Skewness & Kurtosis \\
\hline KSE & .0006 & .0011 & .01694 & & .13 & .26 & -.368 & 5.292 \\
KSE & .0028 & .0070 & .03930 & -.20 & .13 & .33 & -.954 & 3.361 \\
KSE & .0109 & .0164 & .09685 & -.45 & .24 & .69 & -1.132 & 4.294 \\
\hline
\end{tabular}




\subsection{Unit root analysis}

Unit root test is used for the smoothing the time series data and to avoid the misleading inferences for Regression. Our data is stationary at $1^{\text {st }}$ difference. We used both ADF and PP test for confirming the results of Unit Root. ADF test expose the results that null hypothesis of unit root of stock market return of KSE-100 index is influencingly rejected. This reveals that KSE stock market does not show the characteristics of random walk and as such market is not weak form efficient entailing that stock prices remain predictable in daily, weekly and monthly data. Table 2 and Table 3 show unit test for daily and monthly data.

Table 2

The results of unit root test based on daily information

\begin{tabular}{lcccc}
\hline & ADF Level & ADF $1^{\text {st }}$ Difference & PP Level & PP $1^{\text {st }}$ Difference \\
\hline $1 \%$ & -0.45722 & & & \\
\hline $5 \%$ & -3.431981 & -3.431981 & -3.431981 & -3.431981 \\
$10 \%$ & -2.862146 & -2.862146 & -2.862146 & -2.862146 \\
\hline
\end{tabular}

Table 3

The results of unit root test based on monthly information

\begin{tabular}{lcccc}
\hline & ADF Level & ADF $1^{\text {st }}$ Difference & PP Level & PP $1^{\text {st }}$ Difference \\
\hline & -0.45722 & & & \\
\hline $1 \%$ & -3.467418 & -3.467633 & -3.467418 & -3.467633 \\
\hline$\%$ & -2.877729 & -2.877823 & -2.877729 & -2.877823 \\
$10 \%$ & -2.57548 & -2.57553 & -2.57548 & -2.57553 \\
\hline
\end{tabular}

\subsection{One-Sample Kolmogorov-Smirnov Test}

One-Sample Kolmogorov-Smirnov (KS) is used to find out whether probability distribution varies from hypothesized distribution. In one sample case as specified by the null hypothesis the KS test compares the empirical distribution function with cumulative distribution function. The uniform and normal distributions are the fundamental applications for goodness of fit testing.

Daily Market Return: (3598 observations)

Weekly Market Return: (762 observations)

Monthly Market Return: (177 observations)

The other test is associated with one-sample Kologorove-Smirnov test and Table 4 shows details of our findings.

\section{Table 4}

The results of one-sample Kologorove-Smirnov test

\begin{tabular}{lccccc}
\hline Distribution & Absolute & Positive & Negative & K-S Z & Z- Tailed P \\
\hline Normal Daily & .096 & .068 & -.096 & 5.738 & 0.000 \\
Normal Weekly & .094 & .066 & -.094 & 2.589 & 0.000 \\
Normal Monthly & .102 & .073 & -.102 & 1.358 & .050 \\
\hline
\end{tabular}

In case of daily data the results of KS test describe that the p value is ' 0 ' which is lesser $\alpha=.05$, which means the data is not normally distributed. In case of weekly data the results remain same and 
the data is not normally distributed according KS test. But in case of monthly data the p value is .05 which is equals to $\alpha=.05$ and $\mathrm{z}$ value also fall within the range $( \pm 1.96)$ that's mean, here the data is normally distributed and market is weak form efficient in long term scenario. Table 5 shows details of Run Test at $\mathrm{K}=$ Mean Return.

Table 5

The results of Run Test at $\mathrm{K}=$ Mean Return

\begin{tabular}{lccc}
\hline & KSE-100 Index Daily & KSE-100 Index Weekly & KSE-100 Index Monthly \\
\hline $\mathrm{K}=$ Mean & .0006 & .0028 & .0109 \\
Cases $<\mathrm{K}$ & 1732 & 331 & 84 \\
Cases $\geq \mathrm{K}$ & 1867 & 431 & 93 \\
Total Cases & 3599 & 762 & 177 \\
Number of Runs & 1662 & 318 & 83 \\
Z & -4.540 & -4.237 & -.948 \\
Asymp. Sig. (2-tailed) & .000 & .000 & .343 \\
\hline Significant level at 5\% & & &
\end{tabular}

In addition, Table 6 shows Run Test at $\mathrm{K}=0$.

Table 6

Run Test at $\mathrm{K}=0$

\begin{tabular}{lccc}
\hline & KSE-100 Index Daily & KSE-100 Index Weekly & KSE-100 Index Monthly \\
\hline $\mathrm{K}=0$ & .00 & .01 & .02 \\
Cases $<\mathrm{K}$ & 1799 & 381 & 88 \\
Cases $\geq \mathrm{K}$ & 1800 & 381 & 89 \\
Total Cases & 3599 & 762 & 177 \\
Number of Runs & 1692 & 320 & 81 \\
$\mathrm{Z}$ & -3.618 & -4.495 & -1.281 \\
Asymp. Sig. (2-tailed) & .000 & .000 & .200 \\
\hline
\end{tabular}

Total case of runs is significantly less than the expected runs for all types of data under the period review. The null hypothesis is rejected in daily and weekly data because here $p$ value is less than significant level. Its mean here market clearly rejects the random walk hypothesis. However, in monthly data results describe the KSE-100 index is weak form efficient market because $\mathrm{P}$ value is greater than significant level.

\section{Conclusion}

This research was conducted to investigate the weak form efficiency in the Karachi Stock Exchange. For this purpose, daily, weekly and monthly data was taken from July 1997 to April 2012 to check the hypothesis. After applying descriptive statistics, unit root test (which $1^{\text {st }}$ make the data stationary not at level but at $1^{\text {st }}$ difference) Kolmogrov-Smirnov test and run test we found that Karachi stock market of Pakistan is not weak-form efficient in short run time period at daily and weekly prices. It means null hypothesis is rejected because the ' $\mathrm{P}$ ' value is less than " 0.05 " which is significant level. But in long run time period (at monthly data) this market becomes weak form efficient and prove the random walk hypothesis because ' $\mathrm{P}$ ' value is equals to $\alpha=.05$ and $\mathrm{z}$ value also fall within the range $( \pm 1.96)$ that's mean, here the data is normally distributed and market is weak form efficient in long term scenario. 
So we can say that technical analyst can get the benefit from the Karachi Stock Exchange in short time of period but not in long time period. Anyhow there exists the opportunity for the traders to earn high returns and can outperform the market by predicting the upcoming stock prices.

\section{Acknowledgment}

The authors would like to thank the anonymous referees for their comments on earlier version of this paper.

\section{References}

Abraham, A., Seyyed, F., \& Alsakran, S. (2002). Testing the random behavior and efficiency of the gulf stock markets. The Financial Review, 37(3), 469-480.

Agelov, (2009). Testing the weak-form efficiency of the Bulgarian Stock Market. Discussions Paper, $D P / 71 / 2009$

Ahmed, F. (2002). Market efficiency in emerging stock markets: The case of Dhaka Stock Exchange, www.fgda.org/html/savings 2002-1.htm.

Ang, J., \& Pohlman, R. (1978). A note on the price behaviors of Far Eastern Stocks. Journal of International Business Studies, 1, 103 - 107.

Borges, M. R. (2008). Efficient market hypothesis in European Stock Markets. working paper series, WP 20/2008/DE/CIEF, School of Economics and Management, Technical University of Lisbon.

Branes, P. (1986). Thin trading and stock market efficiency: A case of the Kuala Lumpur Stock Exchange. Journal of Business Finance \& Accounting, 13(4), 609-617.

Chan, K.C., Gup, B.E., \& Pan, M.S. (1992). An Empirical Analysis of Stock Prices in Major Asian Markets and United States. The Financial Review, 27(2), 289-307.

Suleman, M.T., Hamid, K., Ali Shah, S.Z., \& Imdad Akkash, R. S. (2010). Testing the weak form of efficient market hypothesis: Empirical evidence from Asia-Pacific Markets (December 1, 2010). International Research Journal of Finance and Economics, 58, 121.

Hawawini, G. (1984). European Equity Markets: Price Behavior and Efficiency. Monograph Series in Finance and Economics (Saloman Center, New York University).

Huang, B. (1995). Do Asian Stock Market prices follow random walks? Evidence form the variance ratio test. Applied Financial Economics, 5, 251 - 256.

Brown, L., \& Easton, A. (1989). Weak-form efficiency in the nineteenth century: A study of daily prices in the London Market for 3 per cent Consols, 1821-1860. Economica 56, 61-70.

Latham, M. (1985). Defining capital market efficiency. Finance working paper 150 Institute for Business and Economic Research, University of California, Berkeley,

Lima, E. J. A., \& Tabak, B.M. (2004). Tests of the random walk hypothesis for equity markets: Evidence from China, Hong Kong and Singapore. Applied Economics Letters, 11, 255-258.

Lo, A., \& Mackinlay, C. (1988). Stock market do not follow random walks: Evidence from a simple specification test. Review of Financial Studies, 1, $41-66$.

Lo, A. W. (1997). Market Efficiency: Stock Market Behaviour in Theory and Practice. Volume I and II, Chethenham, UK. An Elgar Reference Collection.

Mobarek, A., \& Keasey, K. (2000). Weak-form market efficiency of an emerging Market: Evidence from Dhaka Stock Market of Bangladesh. ENBS Conference held on Oslo.

Moustafa, M.A. (2004), Testing the weak-form efficiency of the United Arab Emirates stock market. International Journal of Business, 9(3), 309-325.

Niblock, S., \& Sloan, K. (2007). Are Chinese Stock Markets Weak-form Efficient? Paper presented at the 12th Finsia-Melbourne Centre for Financial Studies Banking and Finance Conference, Melbourne.

Srinivasan, P. (2010). Testing weak-form efficiency of Indian Stock Markets. Asia Pacific Journal of Research in Business Management, 1(2). 
Panday (2003). Efficiency of Indian Stock Market. Time series course.

Rahman, S., \& Hossain, M.F. (2006). Weak form efficiency: Testimony of Dhaka Stock Exchange. Journal of Business Research, 8, 1-12. 